Journal of Computer Science 6 (4): 417-424, 2010

ISSN 1549-3636

C 2010 Science Publications

\title{
A Fuzzy Based Decision Support System for Evaluating Land Suitability and Selecting Crops
}

\author{
${ }^{1}$ Sri Hartati and ${ }^{2}$ Imas S. Sitanggang \\ ${ }^{1}$ Department of Computer Science and Electronics, Faculty of Mathematics and Natural Sciences, \\ Gadjah Mada University, Sekip Utara BLS 21 Yogyakarta 55281, Indonesia \\ ${ }^{2}$ Department of Computer Science, Faculty of Natural Science and Mathematics, \\ Bogor Agricultural University, Indonesia
}

\begin{abstract}
Problem statement: Evaluating land suitability and selecting crops in modern agriculture is of critical importance to every organization. This is because the narrower area of land, the more effectiveness in planting is required in accordance with the desires of the land. Process of evaluating land suitability class and selecting plants in accordance with decision marker's requirements is complex and unstructured. Approach: This study presented a fuzzy-based Decision Support System (DSS) for evaluating land suitability and selecting crops to be planted. A fuzzy rules was developed for evaluating land suitability and selecting the appropriate crops to be planted considering the decision maker's requirements in crops selection with the efficient use of the powerful reasoning and explanation capabilities of DSS. The idea of letting the problem to be solved determines the method to be used was incorporated into the DSS development. Results: As a result, effective decisions can be made for land suitability evaluation and crop selection problem. An example was presented to demonstrate the applicability of the proposed DSS for solving the problem of evaluating land suitability and selecting crops in real world situations. Conclusion: Fuzzy based model can represent and manipulate agriculture knowledge that is incomplete or vague and it can be used to determine land limitation rating. The rating value was used to determine limitation level of the land and used to determine what the most suitable crops to cultivate for the existing condition of the land.
\end{abstract}

Key words: Decision analysis, decision support systems

\section{INTRODUCTION}

Evaluating land suitability and selecting crops in modern agriculture is of critical importance to every organization. This is because the narrower area of land, the more effectiveness in planting is required in accordance with the desires of the land. Process of evaluating land suitability class and selecting plants in accordance with decision marker's requirements is complex and unstructured. DSS is a computer based system utilizes model and data to support decision maker for solving unstructured problems. Tremendous efforts have been spent and significant advances have been made in fuzzy modeling, resulting in the development of numerous methods for solving various decision making problems. These methods are often difficult to classify, evaluate and compare, because they are developed on various assumptions and use of different types of preference information in the problem solving process.
Several methods may often appear to be useful for a particular problem. However, different methods usually represent radically different philosophies in problem solving and choosing an appropriate method for addressing a land suitability evaluation and selection problem may be complex and challenging due to the nature of a particular problem under consideration and the decision maker's requirements and preference in the decision making process (Joerin et al., 2001). There are several system have been developed for land suitability evaluation. For example, EXGIS is a system integrating expert system shell designed for manipulating knowledge on land use suitability for agricultural purposes with GIS, a commercial computer package from ARC/INFO (Yialouris et al., 1997). It is a rulebased expert system for land and climate suitability evaluation in southern part of Greece. Five crops are considered maize, olive, tomato, wheat and grape. Another example is ALES (Rossiter and Van

Corresponding Author: Sri Hartati, Department of Computer Science and Electronics,

Faculty of Mathematics and Natural Sciences, Gadjah Mada University,

Sekip Utara BLS 21 Yogyakarta 55281, Indonesia Tel/Fax: 62-0274-555133 
Wambeke, 1997), a computer program for land evaluation, both physically and economically, following the method of Food and Agriculture Organization (FAO).

The application of DSS for solving structured and semi-structured problems has become increasingly popular nowadays due to its flexibility and adaptability for tackling various decision situations in an effective and efficient manner (Mallach, 2000). The attractiveness of the DSS in real world settings is more enhanced with the provision of a convenient user interfaces and a direct control of the problem solving process by the decision-maker with the availability of various decision making methods. This study discusses a fuzzy modeling for decision support system for physical land suitability for food crops.

\section{MATERIALS AND METHODS}

Land limitations that will be used in the evaluation are limitations that are stated in the FAO sub-class of land suitability classification. Many researchers and practitioners suggested limitation on land preparation as an additional limitation (Ritung et al., 2007; FAO, 1981). Land characteristics are selected from Table 1 in accordance to the limitations being used. System is limited for evaluating mineral soils and not suitable for peat soils. Therefore, land characteristics related to peat soils, such as peat depth and maturity, are not included in the evaluation. In the present study, limitations are grouped into three different sets: climate, landscape and soil, and land preparation.

Data on crop growth requirements are obtained from researches and land mapping activities which have been done so far by various researchers and practitioners in land suitability. Such data have been collected and documented in Puslitbanghorti (Indonesian Center for Horticultural Research Development). Crop requirement data are classified in accordance with land suitability classes: S1 (very suitable), S2 (moderately suitable) and S3 (marginally suitable) class and $\mathrm{N}$ (unsuitable). As an example, requirement for Asparagus (Asparagus officinal is LINN) is shown in Table 2. The correspondence between land suitability class and the limitation level (Ritung et al., 2007) is shown in Table 3.

Table 1: Limitations and land characteristics being used

\begin{tabular}{llll}
\hline Limitation & Land characteristics & Limitation & Land characteristics \\
\hline Climate & Average temperature rainfall air humidity & Physical soil & Texture, coarse fragments, soil depth \\
Landscape and soil & & Soil fertility & Soil CEC (land KTK), pH, bases saturation, C-Organic \\
Topography & Slope & Salinity and alkalinity & Salinity, alkalinity \\
Wetness & Flooding, drainage & Land preparation & Surface rock folded drown of rock \\
\hline
\end{tabular}

Table 2: Data of growth requirement of asparagus

\begin{tabular}{|c|c|c|c|c|}
\hline \multirow[b]{2}{*}{ Land characteristics } & \multicolumn{4}{|l|}{ Land suitability classes } \\
\hline & $\mathrm{S} 1$ & $\mathrm{~S} 2$ & S3 & $\mathrm{N}$ \\
\hline \multicolumn{5}{|l|}{ Temperature } \\
\hline Average temperature $\left({ }^{\circ} \mathrm{C}\right)$ & $18-25$ & $25-30,15-18$ & $30-35,10-15$ & $>35,<10$ \\
\hline \multicolumn{5}{|l|}{ Water availability } \\
\hline Rainfall (mm) & $1000-2000$ & $500-1000,2000-3000$ & $250-500,3000-4000$ & $<250,>4000$ \\
\hline Air humidity (\%) & $>42$ & $36-42$ & $30-36$ & $<30$ \\
\hline \multicolumn{5}{|l|}{ Oxygen availability } \\
\hline Drainage & Well, moderately well & Well, poor & Poor, somewhat excessive & Very poor, excessive \\
\hline \multicolumn{5}{|l|}{ Root-zone } \\
\hline Texture & $\mathrm{f}, \mathrm{sf}, \mathrm{m}$ & $\mathrm{f}, \mathrm{sf}, \mathrm{m}$ & sco & co \\
\hline Coarse fragments $(\%)$ & $0-15$ & $15-35$ & $35-55$ & $>55$ \\
\hline Soil depth $(\mathrm{cm})$ & $>100$ & $75-100$ & $50-75$ & $<50$ \\
\hline \multicolumn{5}{|l|}{ Nutrients } \\
\hline Soil CEC $(\mathrm{cmol})$ & $>16$ & $\leq 16$ & & \\
\hline Bases saturation (\%) & $>35$ & $20-35$ & $<20$ & \\
\hline $\mathrm{PH} \mathrm{H}_{2} \mathrm{O}$ & $5.5-7.8$ & $5.0-5.5,7.8-8.0$ & $<5.0,>8.0$ & \\
\hline C-Organic (\%) & $>1.2$ & $0.8-1.2$ & $<0.8$ & \\
\hline \multicolumn{5}{|l|}{ Toxicity } \\
\hline Salinity ( $\left.\mathrm{ds} \mathrm{m}^{-1}\right)$ & $0-4$ & $4-6$ & $6-8$ & $>8$ \\
\hline \multicolumn{5}{|l|}{ Sodicity } \\
\hline Alkalinity (\%) & $0-15$ & $15-20$ & $20-25$ & $>25$ \\
\hline \multicolumn{5}{|l|}{ Erosion danger } \\
\hline Slope $(\%)$ & $0-8$ & $8-16$ & $16-30$ & $>30$ \\
\hline \multicolumn{5}{|l|}{ Flooding danger } \\
\hline Flooded area & F0 & & & $>\mathrm{F} 1$ \\
\hline \multicolumn{5}{|l|}{ Land preparation } \\
\hline Surface rock $(\%)$ & $0-5$ & $5-15$ & $15-40$ & $>40$ \\
\hline Folded drown of rock $(\%)$ & $0-5$ & $5-15$ & $15-25$ & $>25$ \\
\hline
\end{tabular}

Texture: f: fine; sf: Somewhat fine; m: Moderate; sco: Somewhat coarse; co: Coarse 


\section{J. Computer Sci., 6 (4): 417-424, 2010}

Table 3: Relationship between land suitability class and limitation level

\begin{tabular}{ll}
\hline Land suitability class & Limitation level \\
\hline S1: Very suitable & $0:$ No \\
& $1:$ Slight \\
S2: Moderately suitable & 2: Moderate \\
S3: Marginally suitable & $3:$ Severe \\
N: Unsuitable & $4:$ Very Severe \\
\hline
\end{tabular}

Applying a DSS for effectively Land Suitability evaluation and crop selection problem is not only desirable, but also important. The DSS provides the decision maker with effective mechanisms to better understand the decision problem and the implications of their decision behaviors to the organization by allowing them to interactively exchange information between the system and themselves (Mallach, 2000; Smith, 1992; Wei et al., 2007). Due to the diversity and complexity of the selection criteria, their interrelationships and the volume of information, the DSS has to be efficient, effective and flexible for effectively solving the general selection problem. The DSS is designed to help the decision maker choose the appropriate crops in a flexible and user-friendly manner by allowing the decision maker to input values to express his/her requirements and to fully explore the relationships between the criteria, the alternatives, the methods available and the outcome of the selection process.

The DSS consists of three major subsystems, namely, (a) the dialogue subsystem, (b) the input management subsystem and (c) the knowledge management subsystem which is consistent with the general architecture of DSS. The dialogue subsystem serves to integrate various other subsystems as well as to be responsible for user-friendly communications between the DSS and the decision maker. The subsystem coordinates all functions or commands selected by the decision maker. The interface provides flexibility for customizing the system by the decision maker, the interface is designed so that the decision maker can create, modify or eliminate criteria, or even define which criteria he/she intends to inquire about. A decision maker utilizes the database through the dialogue subsystem for analyzing different alternatives using the knowledge management subsystem.

The input management subsystem organizes and manages all the inputs for solving the land suitability evaluation and crop selection problem. The type and the quantity of data inputs for solving the problem vary typically from one problem to another. The input data are entered into the system for processing and they can also be edited after they have been entered into the system. It should be noted that the system is flexible to allow new data types to be added to the system due to the possible addition of new methods in the DSS.
Table 4: Linguistic values of land characteristics

\begin{tabular}{|c|c|}
\hline Land characteristics & Linguistic fuzzy words \\
\hline $\begin{array}{l}\text { Average } \\
\text { temperature }\end{array}$ & $\begin{array}{l}\text { Cold, somewhat cold, cool, medium, warm, } \\
\text { somewhat hot, hot }\end{array}$ \\
\hline ainfall & $\begin{array}{l}\text { Very low, low, moderately low, moderate, } \\
\text { moderately high, high, very high }\end{array}$ \\
\hline Air humidity & $\begin{array}{l}\text { Very low, low, moderately low, moderate, } \\
\text { moderately high, high, very high }\end{array}$ \\
\hline lope & Flat, undulating, rolling, hilly, mountainous \\
\hline ts & ly low, moderately high, high \\
\hline oil depth & $\begin{array}{l}\text { Shallow, somewhat shallow, somewhat } \\
\text { deep, deep }\end{array}$ \\
\hline Soil CEC & Low, 1 \\
\hline $\mathrm{pH} \mathrm{H}_{2} \mathrm{O}$ & $\begin{array}{l}\text { Strongly acid, weakly acid, neutral, weakly } \\
\text { bases, strongly bases }\end{array}$ \\
\hline Base: & Low, medium, high \\
\hline & lium, high \\
\hline & Low, \\
\hline & ely high, high \\
\hline & Low, moderately low, moderately high, high \\
\hline Folded drown of rock & Low, moderately low, moderately high, high \\
\hline
\end{tabular}

Table 5: Limitation level and rating

\begin{tabular}{lll}
\hline $\begin{array}{l}\text { Average } \\
\text { temperature interval }\end{array}$ & Land suitability & Limitation level \\
\hline$<10.5$ & Unsuitable (N) & Very severe \\
$9.5-15.5$ & Marginally suitable (S3) & Severe \\
$14.5-18.5$ & Moderately suitable (S2) & Moderate \\
$17.5-25.5$ & Very suitable (S1) & Slight \\
$24.5-30.5$ & Moderately suitable (S2) & Moderate \\
$29.5-35.5$ & Marginally suitable (S3) & Severe \\
$>34.5$ & Unsuitable (N) & Very severe \\
\hline
\end{tabular}

The knowledge management subsystem manages all the fuzzy methods available in the DSS. For the sake of describing the proposed DSS, fuzzy methods have been included in the proposed DSS for helping assist the decision maker select the most appropriate crop to be planted. The proposed DSS consists of four phases, including (a) identification of the decision maker's requirements, (b) determination of membership functions of each criteria, (c) determination of performance rating of each of land limitation, (d) determination of performance rating of landscape and soil limitation, (e) evaluation of land suitability class and (f) selecting the appropriate crop.

In this research there are many linguistic fuzzy words, some of which are related to land characteristics which is shown in Table 4, and for the land suitability and for its limitation level is shown respectively in Table 5. The fuzzy set membership functions represent the average temperature are defined based on the knowledge of human expert and knowledge from (Ritung et al., 2007; FAO, 1981) and the equations representing the functions are written in (1-7). The fuzzy sets representing the rainfall, humidity and other land characteristic are defined in the same manner: 
$\mu_{\text {cold }}$ (at) $=\left\{\begin{array}{cl}1, & \text { at } \leq 9.5 \\ 10.5-\text { at, } & 9.5<\text { at } \leq 10.5 \\ 0, & \text { otherwise }\end{array}\right.$

$\mu_{\text {somewhat_cold }}$ (at) $=\left\{\begin{array}{cl}1, & 10.5<\text { at } \leq 14.5 \\ \text { at }-9.5, & 9.5<\text { at } \leq 10.5 \\ 15.5-\text { at, } & 14.5<\text { at } \leq 15.5 \\ 0, & \text { otherwise }\end{array}\right.$

$\mu_{\text {cool }}($ at $)=\left\{\begin{array}{cc}1, & 15.5<\text { at } \leq 17.5 \\ \text { at }-14.5, & 14.5<\text { at } \leq 15.5 \\ 18.5-\text { at, } & 17.5<\text { at } \leq 18.5 \\ 0, & \text { otherwise }\end{array}\right.$

$\mu_{\text {medium }}($ at $)=\left\{\begin{array}{cl}1, & 18.5<\text { at } \leq 24.5 \\ \text { at }-17.5, & 17.5<\text { at } \leq 18.5 \\ 25.5-\text { at, }, & 24.5<\text { at } \leq 25.5 \\ 0, & \text { otherwise }\end{array}\right.$

$\mu_{\text {cool }}($ at $)=\left\{\begin{array}{cc}1, & 15.5<\text { at } \leq 17.5 \\ \text { at }-14.5, & 14.5<\text { at } \leq 15.5 \\ 18.5-\text { at, } & 17.5<\text { at } \leq 18.5 \\ 0, & \text { otherwise }\end{array}\right.$

$\mu_{\text {somewhat_hot }}($ at $)=\left\{\begin{array}{cl}1, & 30.5<\text { at } \leq 34.5 \\ \text { at }-29.5, & 29.5<\text { at } \leq 30.5 \\ 35.5-\text { at }, & 34.5<\text { at } \leq 35.5 \\ 0, & \text { otherwise }\end{array}\right.$ $\mu_{\text {hot }}($ at $)=\left\{\begin{array}{cl}1, & \text { at }>35.5 \\ \text { at }-34.5, & 34.5<\text { at } \leq 35.5 \\ 0, & \text { otherwise }\end{array}\right.$

In fuzzy modeling for decision support systems for evaluating land suitability there are three interdependent steps: fuzzyfication, inference and defuzzyfication. A successful execution of these steps leads to the solution of the problem. The heart of fuzzy based system is knowledge base consisting of so-called fuzzy if then rules. A fuzzy if then rule is an if then statement in which some words are characterized by continuous membership functions (Smith, 1992; Wang, 1997). An example of fuzzy rules modeling land suitability for average temperature, rainfall and air humidity is shown in Fig. 1.

All land characteristics are considered as having defined fuzzy sets. Hence the real valued input variables are transformed into fuzzy sets. This stem is applied to each land characteristic factor considered in the solution of the problem. The next step is inference process, in fact, it relates systematically pair wise all the factors that take place in the solution depending on the purpose of the problem. In fact this part includes many fuzzy conditional statements to describe a certain situation.

Land suitability class is determined through a twophase inference based on input data expressed as crisp value and fuzzy set. First, inference process is done to set the limitation level and secondly it is done to determine the suitability class of the land. These two processes are depicted in Fig. 2.

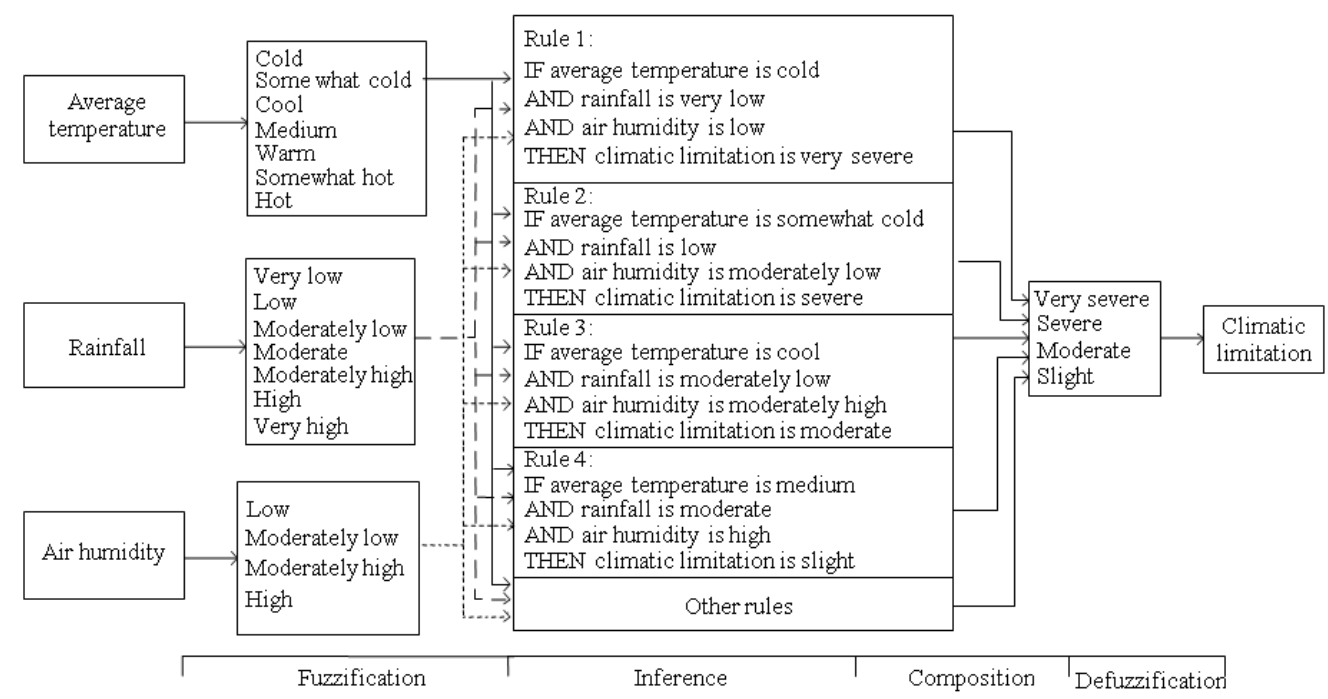

Fig. 1: Determination of limitation associated with climate 


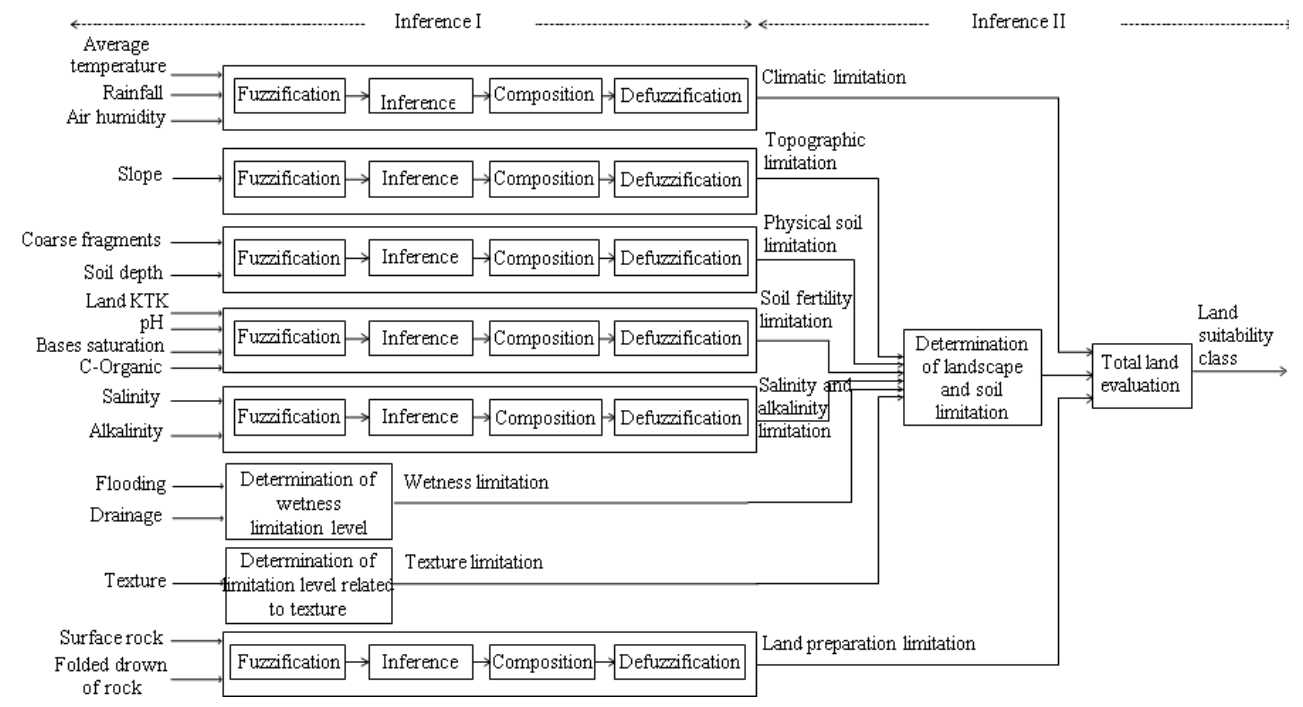

Fig. 2: Computing of limitations of fuzzy based DSS for land suitability evaluation

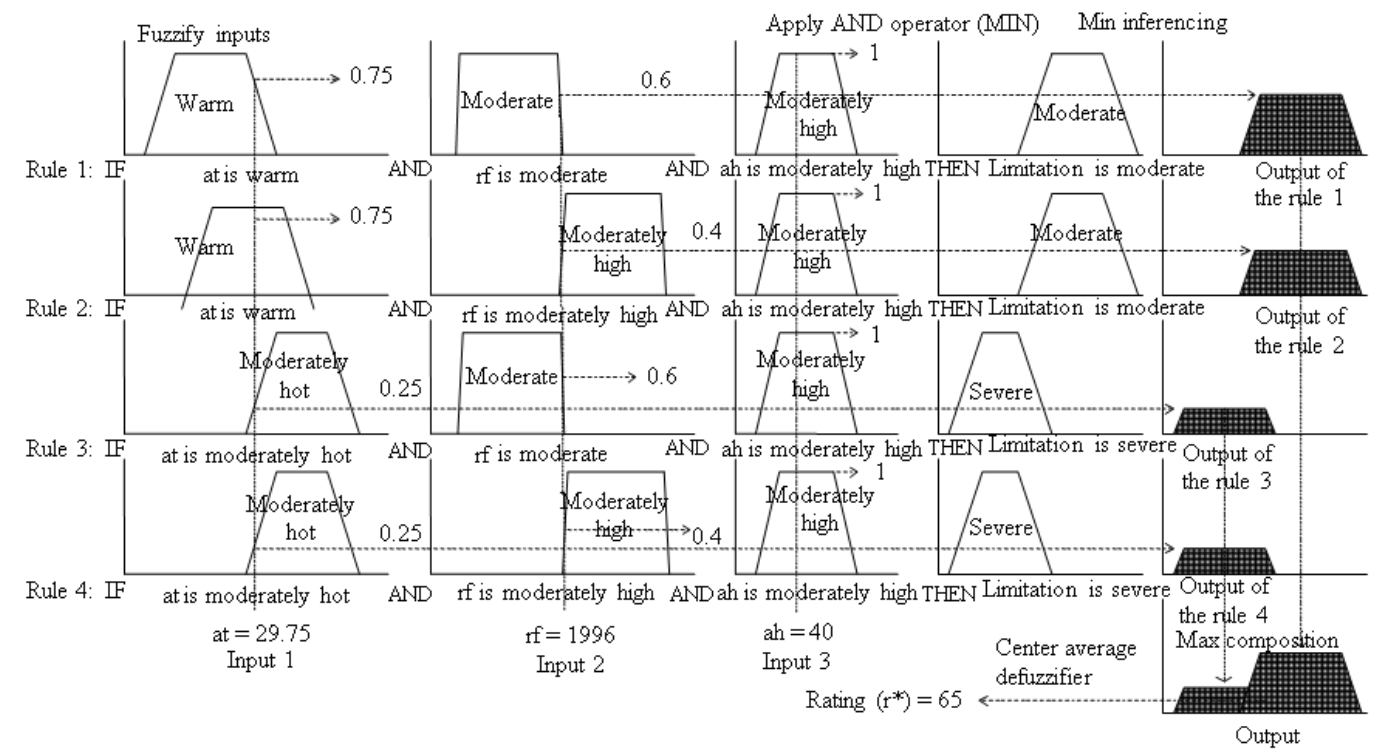

Fig. 3: Maximum composition of rules

In phase I inference, limitation level is concluded from inputted values of land characteristics. For land characteristics expressed as linguistic variables, i.e., characteristics related to climate, topography, physical soil (except soil texture), soil fertility, salinity and alkalinity and land preparation, limitation level is obtained from fuzzy inference. For illustration, a portion of the inference process to set these limitation levels based on input of crisp values, associated with climate, is illustrated in Fig. 3. Based on fuzzy inference, there are four phases in limitation level setting from crisp value input, namely fuzzyfication, inference, composition and defuzzyfication. Inference method adopted in the present research is min, while max is used for the composition. Combination of the two is own as max-min inference. This method is widely used in inference engine using fuzzy system due to its easiness in computation (Kiszka et al., 1985; Karray and Silva, 2004; Wei et al., 2007). The membership function of the limitation level is derived from the generated rules, truncated at the height corresponding to the computed truth premise value using the respective rules such as shown Fig. 3. The climatic limitation rating crisp data is obtained using 
max composition method, which is composited from maximum points of all fuzzy sets generated from the results of min inference such as shown in the Fig. 7. The result of maximum composition then is used to calculate the deterministic value of a linguistic variable, the center average defuzzyfier is applied (Kiszka et al., 1985; Karray and Silva, 2004) as follows.

Supporse $\mathrm{y}^{-\mathrm{k}}$ is a center of the $\mathrm{k}^{\text {th }}$ fuzzy sets and $\mathrm{w}_{\mathrm{k}}$ signifies the height, then, the center average defuzzyfier determines $y^{*}$ as:

$$
y^{*}=\frac{\sum_{k=1}^{M} y^{-k} w_{k}}{\sum_{k=1}^{M} w_{k}}
$$

\section{RESULTS}

To demonstrate the applicability of the proposed DSS, a problem of evaluating land suitability and selecting crops, the input data are given either in crisp values or in fuzzy sets. As an example, given a set of crisp input data such as shown in Fig. 4, the fuzzy based DSS carried out four phases in determining the total land evaluation namely fuzzyfication, inference, composition and defuzzyfication described above. The max-min inference method is adopted in for the composition rules. This method is widely used in inference engine using fuzzy system due to its easiness in computation (Karray and Silva, 2004). The defuzzyfication method used in the study is center average defuzzyfier. It is easier to implement compared to the other two, center gravity and maximum defuzzyfier. The system results in the total land evaluation is shown in Fig. 5 and the total land evaluation is moderately suitable (S2) for crop of asparagus. Figure 6 shows the asparagus crop's requirements are given by the system. The system receives fuzzy input as well, such as shown in Fig. 7.
The results of some testing data are summarized in Table 6 . Table 6 indicates the land suitability class for each crop related to climate as well as landscape and soil.

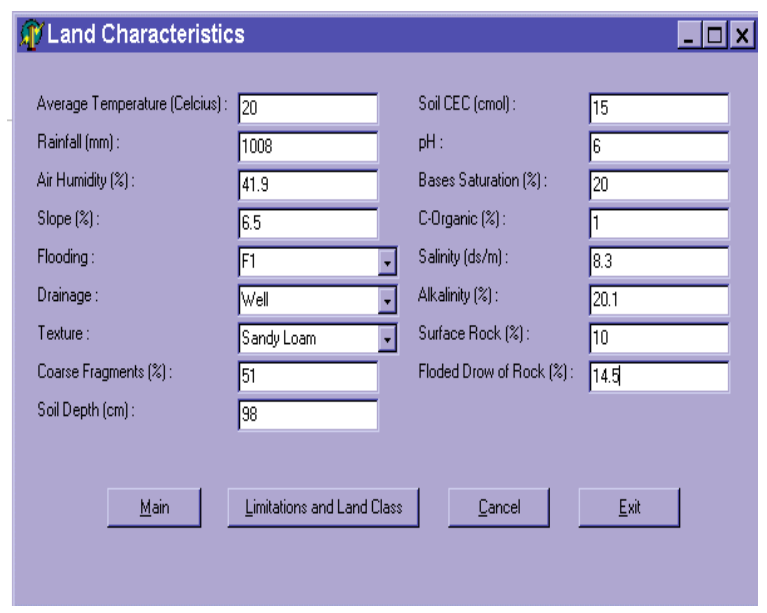

Fig. 4: Example of crisp input data

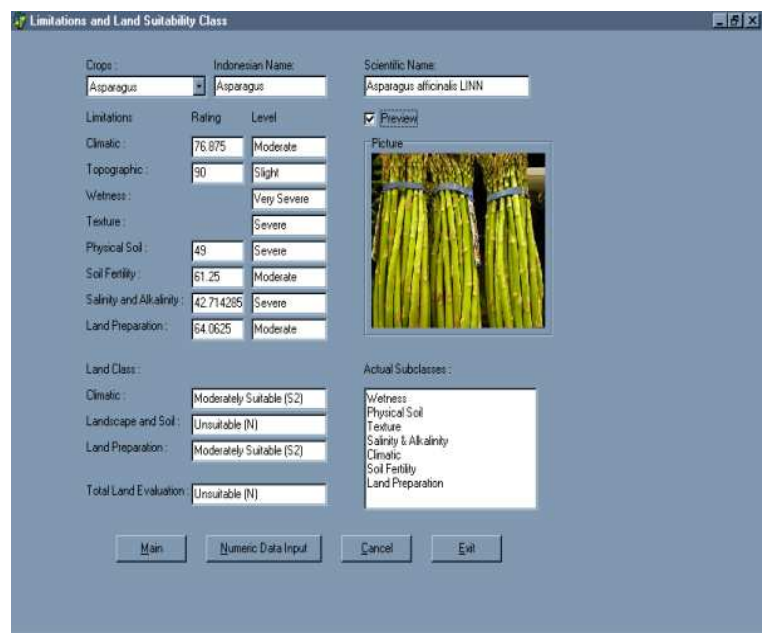

Fig. 5: Example of output

Table 6: Land suitability class associated with climate, landscape, soil for crisp input data

\begin{tabular}{|c|c|c|c|}
\hline $\begin{array}{l}\text { Climatic } \\
\text { class }\end{array}$ & Crops & $\begin{array}{l}\text { Landscape } \\
\text { and soil class }\end{array}$ & Crops \\
\hline$\overline{\mathrm{S} 1}$ & -- & S1 & -- \\
\hline S2 & $\begin{array}{l}\text { Asparagus, aster, star fruit, gladiolus, corn, citrus, } \\
\text { peanut, soybean, cananga, quinine, klengkeng fruit, } \\
\text { mango, rose, pineapple, bitter melon, papaya, } \\
\text { tuberosa, strawberry, tobacco, sweet potato }\end{array}$ & S2 & -- \\
\hline S3 & $\begin{array}{l}\text { Spinach, bean, durian fruit, mung bean, long bean, } \\
\text { cinnamon, radish, water melon, cucumber, banana, } \\
\text { cantaloupe, egg plant, tomato, carrot }\end{array}$ & S3 & $\begin{array}{l}\text { Broccoli, corn, cotton, cinnamon, soybean, cabbage, pepper, } \\
\text { gnetum gnemon, water melon, cucumber, nutmeg, bitter } \\
\text { melon, cantaloupe, egg plant, tomato, sweet potato }\end{array}$ \\
\hline $\mathrm{N}$ & $\begin{array}{l}\text { Apple, broccoli, cotton, cabbage, pepper, gnetum } \\
\text { gnemon, nutmeg, petsai, leaf mustard, lettuce, tea. }\end{array}$ & $\mathrm{N}$ & $\begin{array}{l}\text { Apple, asparagus, aster, spinach, star fruit, bean, durian fruit, } \\
\text { gladiolus, citrus, mung bean, long bean, peanut, cananga, } \\
\text { quinine, klengkeng fruit, radish, mango, rose, pineapple, } \\
\text { papaya, petsai, banana, leaf mustard, tuberosa, lettuce, } \\
\text { strawberry, tea, tobacco, carrot }\end{array}$ \\
\hline
\end{tabular}




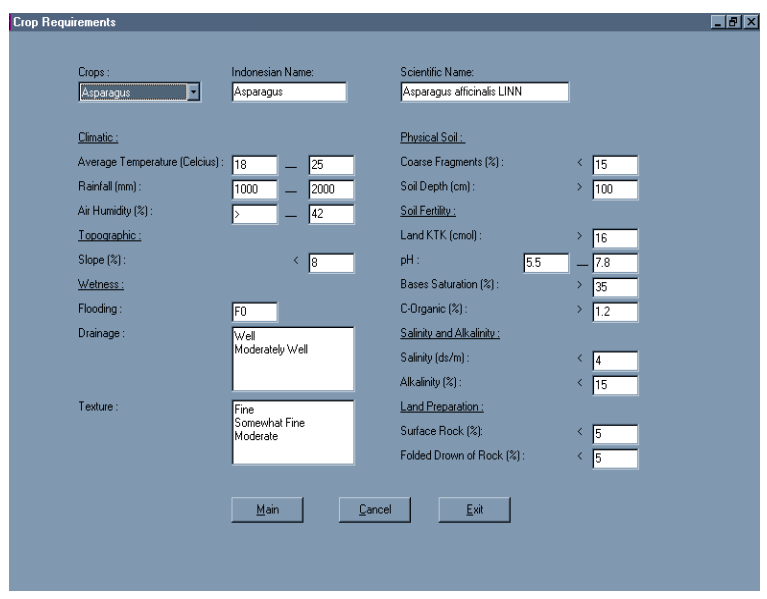

Fig. 6: Crop requirements

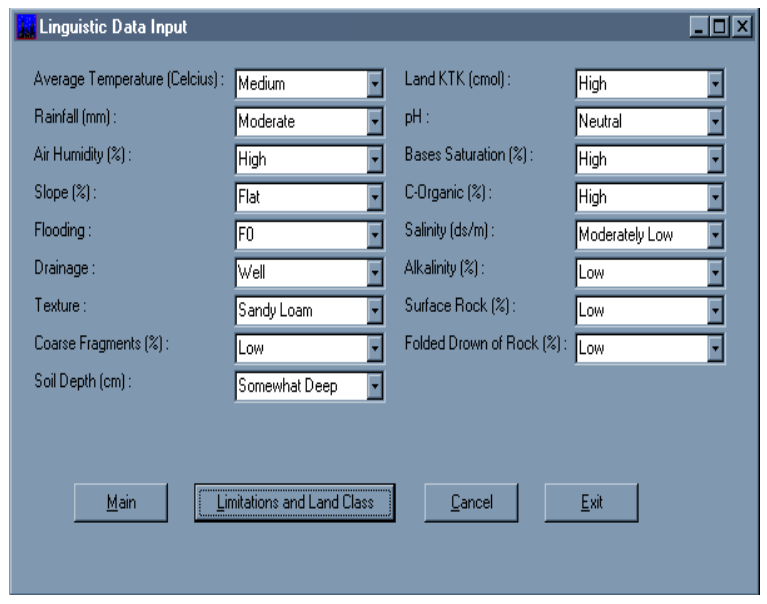

Fig. 7: Example of fuzzy input data

\section{DISCUSSION}

The developed system has been evaluated by the experts from Faculty of Agriculture both Gadjah Mada University and Soil and Agro climate Research Center Bogor, the result shows that it is capable of determining the land suitability class given the characteristics of the land, therefore, it can determine the appropriate crops to be cultivated. In addition, the system is also capable of determining the appropriate land characteristic for a given types of crops.

Fuzzy based model can represent and manipulate agriculture knowledge that is incomplete or vague and it can be used to determine land limitation rating. The rating value is used to determine limitation level of the land. At the similar limitation level for different types of crops, the rating value is used to determine what the most suitable crops to cultivate for the existing condition of the land. The greater the rating value the more suitable crop for land of interest.

\section{CONCLUSION}

The developed DSS has the ability to determine land suitability class for agricultural purposes based on land characteristics being data inputted, i.e., climate, topography, wetness, physical soil, soil fertility, salinity and alkalinity, and land preparation.

The experimental results shows that land suitability classification based on the fuzzy model agrees with the classification made by experts in land suitability classification.

The fuzzy inference processes was used to define land limitation rating, which turn to determine limitation level of the corresponding characteristic. For similar limitation level, rating value was used to determine what crop production most suitable to the existing condition of the land. With greater rating limitation of a crop, the greater the suitability of the crop for the land of interest.

\section{REFERENCES}

FAO, 1981. A Framework for Land Evaluation. 2nd Edn., FAO, ISBN: 92-5-100111-1, pp: 7-21.

Joerin, F., M. The'riault, and A. Musy, 2001. Using GIS and outranking multicriteria analysis for landusesuitability assessment. Int. J. Geogr. Inform. Sci., 15: 153- 174.

Karray, F.O. and C. Silva, 2004. Soft Computing and Intelligent Systems Design, Theory, Tools, and Applications. Pearson Education Limited, pp: 68.

Kiszka, J.B., M.E. Kochanska and D.S. Sliwinska, 1985. The influence of some fuzzy implication operators on the accuracy of fuzzy model. Part II: Fuzzy Sets Syst., 15: 223-240.

Mallach, E.G., 2000. Decision Support and Data Warehouse Systems. McGraw-Hill, ISBN: 0-07289981-6, pp: 148.

Ritung, S., F.A. Wahyunto and H. Hidayat, 2007. Guidelines Land Suitability Evaluation with a case map of Aceh Barat District. Indonesian Soil Research Institute and World Agroforestry Centre, ISBN: 979-3198-36-1, pp: 8-17.

Rossiter, D.G. and A.R. Van Wambeke, 1997. Automated Land Evaluation System. ALES Version 4.65 User's Manual. Itc. http://www.itc.nl/ rossiter/Docs/ALES_V4.65_Ma nual.pdf

Smith, P.N., 1992. Fuzzy evaluation of land-use and transportation options. Environ. Plann., 19: 525-544. 
Wang, L., 1997. A Course in Fuzzy Systems and Control. Prentice-Hall, ISBN: 0-13-593005-7, pp: 105.

Wei, C.C., G.S. Liang and M.J. Wang, 2007. A comprehensive supply chain management project selection framework under fuzzy environment. Int. J. Project Manage., 25: 627-636.
Yialouris, C.P., K. Vassiliki, A.L. Nikos, K. Dionisios and B.S. Alexander, 1997. An integrated expert geographical information system for soil suitability and soil evaluation. J. Geogr. Inform. Dec. Anal., 1: 90-100. 